\title{
A study of the changes in how medically related events are reported in Japanese newspapers
}

This article was published in the following Dove Press journal:

Risk Management and Healthcare Policy

10 August 2010

Number of times this article has been viewed

\author{
Yukiko Kishi' \\ Naoko Murashige ${ }^{2}$ \\ Yuko Kodama' \\ Tamae Hamaki' \\ Kazuhiro Murata ${ }^{3}$ \\ Haruka Nakada' \\ Tsunehiko Komatsu ${ }^{3}$ \\ Hiroto Narimatsu ${ }^{1,4}$ \\ Masahiro Kami' \\ Tomoko Matsumura' \\ 'Division of Social Communication \\ System for Advanced Clinical \\ Research, the Institute of Medical \\ Science, the University of Tokyo, \\ Tokyo, Japan; ${ }^{2}$ Ministry of Health, \\ Labor and Welfare, Aide of the \\ Minister, Health Sector Reform \\ Office, Tokyo, Japan; ${ }^{3}$ Department \\ of Hematology, Teikyo University \\ Chiba Medical Center, Chiba, Japan, \\ ${ }^{4}$ Advanced Molecular Epidemiology \\ Research Institute, Faculty of \\ Medicine, Yamagata University, \\ Yamagata, Japan
}

Correspondence: Hiroto Narimatsu Advanced Molecular Epidemiology Research Institute, Faculty of Medicine, Yamagata University 2-2-2, Lida-Nishi Yamagata, Yamagata, 990-9585, Japan Tel +8I-(0)23-628-5260

$\mathrm{Fax}+8 \mathrm{I}-(0) 23-628-526 \mathrm{I}$

Email hiroto-narimatsu@umin.net URL http://gcoe.id.yamagata-u.ac.jp/

\begin{abstract}
Media reports of medically related events have a major effect on the healthcare community but there have been few detailed investigations conducted to investigate their content. The Nikkei Telecom 21 database was used to investigate the number of reports concerning medically related events between 1992 and 2007 in Japan's 5 national newspapers. For this period, both the total number of articles and the number of articles containing medically-related keywords were determined. The number of reports relating to medically related occurrences increased sharply from 1999 to 2000 and displayed a decrease from 2003 before increasing again in 2008 . As of 2008 , such reports account for $0.17 \%$ of total newspaper articles. The use of the word 'iryokago' (medical professional negligence or error) drastically increased in 1999 but showed a consistent decrease from 2004. On the other hand the frequency of reports relating to 'litigation' and 'punishment' increased rapidly in 1999 before leveling off. Despite this, the number of articles relating to medically related occurrences that were caused by doctor shortages and system errors increased sharply between 2006 and the present. Results indicate that the manner in which newspapers report medically related events is undergoing major changes.
\end{abstract}

Keywords: coverage, incident, doctor shortage, system error, litigation

Medically related events represent a major problem for the healthcare community. In the United States, the healthcare provision system is influenced by the medical malpractice insurance crisis that occurred in the early $1970 \mathrm{~s} .{ }^{1}$ Society's interest in this issue increased further due to the medically related occurrence that took place at the Dana-Farber Cancer Institute in $1994 .^{2}$ In this particular case, a breast cancer patient was administered an overdose of an anticancer drug and, as this patient was also the health columnist for the Boston Globe newspaper, the story was elevated to the front page. This incident prompted the United States to review and improve medically related occurrence measures ${ }^{3}$ and stimulated research into the media coverage of medically related occurrences. ${ }^{4}$

Meanwhile, high-profile medical institutions in Japan have been accused of negligence and committing errors ${ }^{5}$ following a string of medically related occurrences including two 1999 cases in which a patient was administered a fatal IV drip at the Tokyo Metropolitan Hiroo Hospital and in which surgery was performed on the wrong patient at the Yokohama City University Hospital, ${ }^{6}$ and a 2001 case in which a heart-lung machine malfunctioned during heart surgery at the Tokyo Women's Medical University. ${ }^{7}$ The Tokyo Metropolitan Hiroo Hospital incident was also treated as a criminal case in which the hospital director and nurses were found guilty at the Supreme Court in 2004. By contrast, the Tokyo Women's Medical University incident was also treated as a criminal case but all defendants were found not guilty in 2009. During this period, the 
number of medical litigation cases in Japan also increased, with the number of new cases filed rising from 678 in 1999 to 1110 in 2004. ${ }^{8}$ As in the United States, Japan also reinforced its medical safety measures as a result of such events. ${ }^{9,10}$

In 2006 an obstetrician at the Fukushima Prefectural Ono Hospital was arrested in Japan. ${ }^{11}$ In this incident, the doctor in charge was arrested for professional negligence and involuntary manslaughter after a patient suffering from both placenta accreta and placenta previa died while undergoing a caesarian section procedure. As a result of this incident, many physicians were concerned that attending doctors who lost patients may face criminal charges even in the absence of negligence. This caused many doctors to turn to practicing defensive medicine or to abandon the specialty of obstetrics, which has a high risk of litigation. As time passed, the same mass media that was initially critical of the arrested physician began to report that the incident had had a destructive effect on Japan's obstetric care system.

Media reports into medically related occurrences have a major effect on the healthcare community. ${ }^{12}$ Imposing safety measures on the healthcare community will also serve to invite the practice of defensive medicine. Physicians sincerely wish for the reporting of medical accidents to be conducted in a manner that is both accurate and appropriate. However, until now there have been few detailed investigations conducted into the media coverage of medical accidents. ${ }^{4,13}$ However, until now there have been a few detailed investigations conducted into the media coverage of medical accidents; Stebbing et al analyzed newspaper coverage of pediatric medication errors and adverse drug events in many countries. ${ }^{4}$ These researchers concluded that media coverage of pediatric medication safety has increased in the past 10 years and that reporting of patient safety failures was generally fair, and reports were generally framed in light of a culture of safety. Another investigation is that carried out by Lupton et al, in which a systematic and comprehensive analysis of the representation of doctors and the medical practice in metropolitan Australian newspapers and major news magazines was reported. ${ }^{13}$ These authors reported that malpractice and medical negligence/mistakes are the most frequent medical topic.

In this study, we conducted an investigation of the current state of medical occurrence reports in Japanese newspapers.

\section{Method}

\section{Search method}

The Nikkei Telecom 21 (http://telecom21.nikkei.co.jp/) database was used to identify articles containing the word 'iryojiko' (medically related occurrence, event, or incident) or 'iryokago' (medical professional negligence or error). The basic Nikkei Telecom 21 database contains the article content of newspapers published within Japan. When a search word is inputted, the relevant data is identified from the areas 'title', 'content', and 'keywords'. Those articles containing the following keywords were then selected from the search results.

\section{Hospital related}

Ono Hospital; Tokyo Women's Medical University; Yokohama City University; university hospital; prefectural hospital; public hospital; private hospital; medical corporation; practice.

\section{Litigation related}

lawyer; trial; civil; damages; compensation; victim.

\section{Punishment related}

Professional negligence; police; criminal; prosecution; filing charges; administrative penalty; Medical Ethics Council.

\section{Healthcare system/medical accident cause investigation related}

Ministry of Health, Labor, and Welfare; National Police Agency; Ministry of Justice; medical accident investigation; independent committee; healthcare safety investigation committee; healthcare system collapse; doctor shortage; system error; reduction of healthcare costs; uneven distribution; passing the buck, overwork.

\section{Newspapers investigated}

From the newspapers included in the database, we selected the 'Asahi Shimbun', 'Mainichi Shimbun', 'Yomiuri Shimbun', 'Sankei Shimbun', and 'Nihon Keizai Shimbun'. These are the five largest national newspapers in Japan and have a combined circulation of between 2,190,000 and 10,020,000. The database includes complete archives for all of these newspapers but the earliest year available is 1992 so this was selected as the starting point for our investigation.

\section{Research objectives}

We aimed to assess the changes in society's awareness of medically related occurrences by investigating the number of articles relating to medical accidents and the annual trends thereof within Japan's major national newspapers.

\section{Results}

\section{Total articles}

Annual trends in the total number of articles in each of the five newspapers studied are displayed in Figure 1. The total 
number of articles in the database increased during the first half of the 1990s and leveled off after 2001. From the year 2000, approximately three times more article data is included for the Asahi, Yomiuri, and Mainichi newspapers than for the Nikkei and Sankei newspapers.

\section{Articles containing the word 'iryojiko' (medically related occurrence, event, or incident)}

Annual trends for the number of articles containing the word 'iryojiko' are shown in Figure 2 and displayed as a proportion of the total number of articles in Figure 3. In all newspapers studied, the number of articles increased sharply between 1999 and 2000 and displayed a decrease from 2003 before increasing in 2008. In 2008, the number of articles containing the word 'iryojiko' numbered 1978; accounting for $0.16 \%$ of the total number of articles.

\section{Articles containing the word 'iryokago' (medical professional negligence or error)}

Annual trends for the number of articles containing the word 'iryokago' are shown in Figure 2 and displayed as a proportion of the total number of articles in Figure 3. In all newspapers studied, the number of such articles showed a consistent decrease from the year 2003. In 2008, the number of articles that included the word 'iryokago' numbered 673 ; accounting for $0.052 \%$ of the total number of articles.

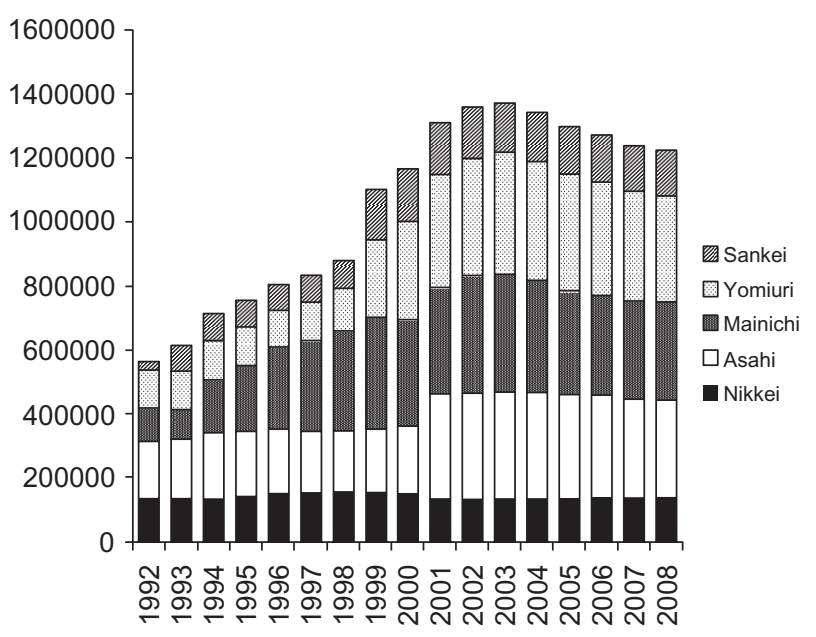

Figure I Total number of articles in each newspaper.

\section{Newspaper comparisons}

The use of the word 'iryojiko' increased around the year 2000 before leveling off. Major differences were observed in usage frequency between newspapers. The newspaper containing the highest proportion of articles that include the word 'iryojiko' is the Yomiuri Shimbun, with approximately twice as many mentions as each of the other newspapers (Figure 3) studied. On the other hand, there were no major differences between newspapers regarding the usage frequency of the word 'iryokago', with all newspapers showing a recent decreasing trend.

\section{Annual keyword trends}

Annual trends in the number of articles containing each keyword are displayed in Figure 4. From 1998 to 2003, the transient increase in the number of reports into specific incidents such as those at the Tokyo Women's Medical University and the Tokyo Metropolitan Hiroo Hospital were observed for the years in which these cases occurred. On the other hand, there were more reports regarding the Fukushima Prefectural Ono Hospital case in 2008 than when the event occurred actually in 2006 (Figure 4A). The number of reports relating to 'litigation' and 'punishment' increased rapidly from 1999 before leveling off (Figures 4B and C). Despite this, the number of articles relating to incidents caused by 'iryojiko' and 'iryokago' rose sharply from 2006 (Figure 4D).

\section{Discussion}

Our results indicate there have been changes in how newspapers in Japan cover medically related occurrences. As can be seen in Figure 2, the number of Japanese reports relating to this issue increased rapidly following the Tokyo Metropolitan Hiroo Hospital incident ${ }^{14}$ in 1999. The heightened public interest created by an increase in the number of newspaper reports stemming from this specific medically related occurrence is similar to what occurred in the United States. ${ }^{2,15}$ Particular attention must be paid to the fact that, during this incident, the expression 'iryokago' (medical professional negligence or error) was used in the majority of Japanese newspaper articles even before accurate investigations had been conducted. This expression that assumes negligence on the part of the healthcare worker was used before the truth of the incident had been fully elucidated and it is highly likely that such sensationalist newspaper coverage creates preconceptions regarding a case. It is the mass media that makes the general public aware of the occurrence of medical accidents, and there are some constant characteristics in how the mass media covers medical accidents. This is something that healthcare workers should be aware of. 


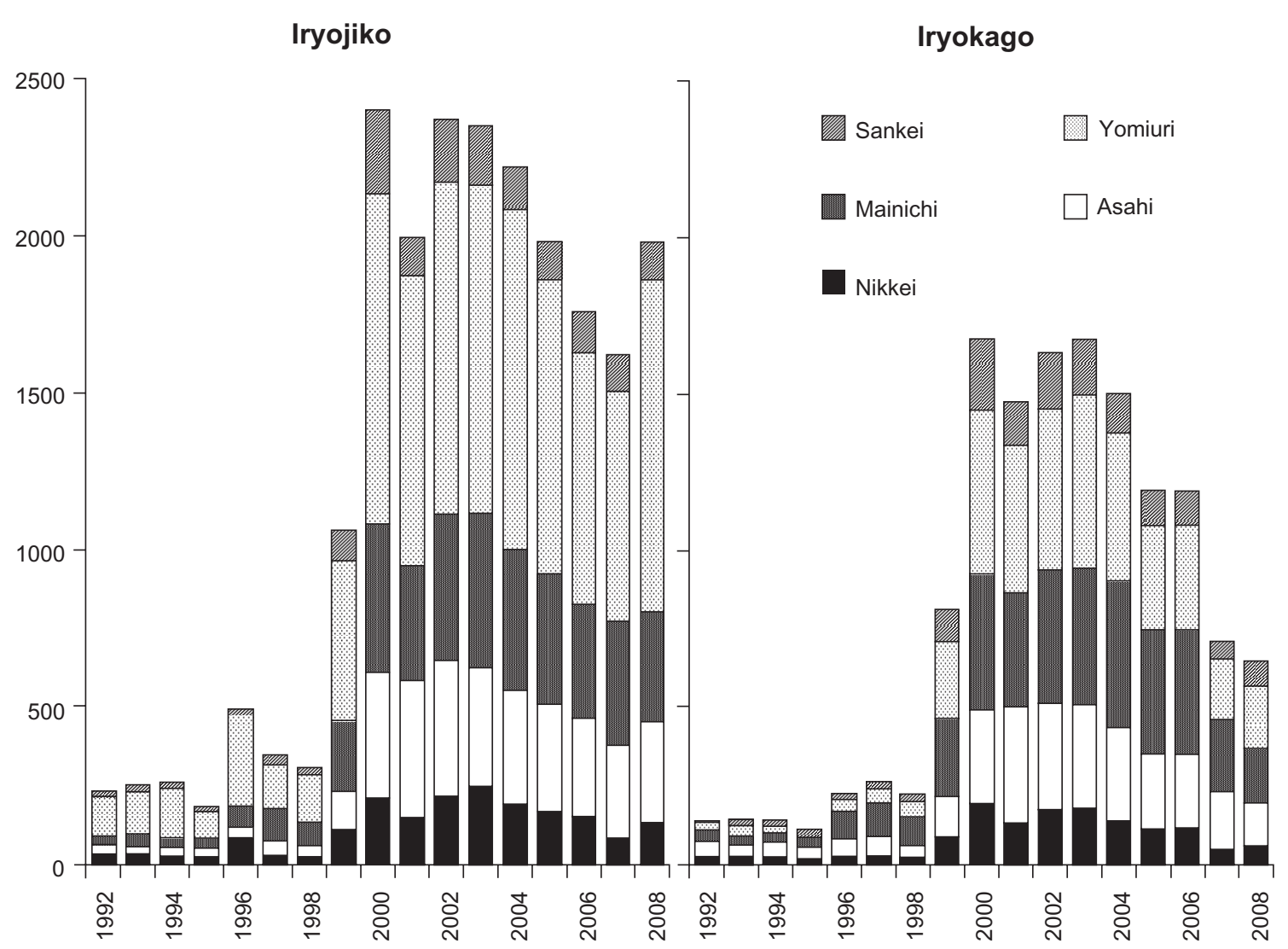

Figure 2 Number of articles containing the word 'iryojiko' (medically related occurrence or incident) or 'iryokago' (medical professional negligence or error).

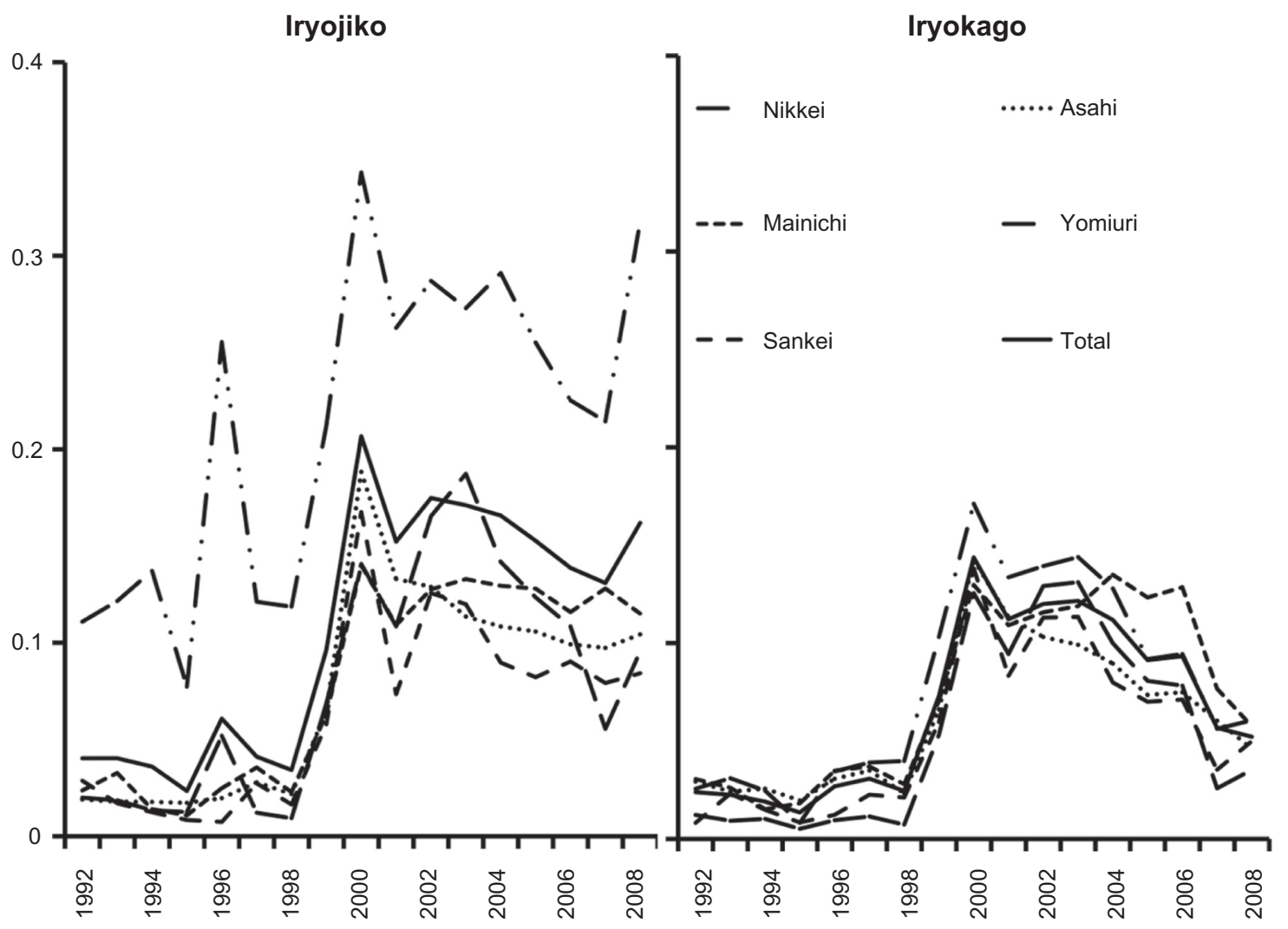

Figure 3 Proportion of articles containing the word 'iryojiko' (medically related occurrence or incident) or 'iryokago' (medical professional negligence or error). 
A

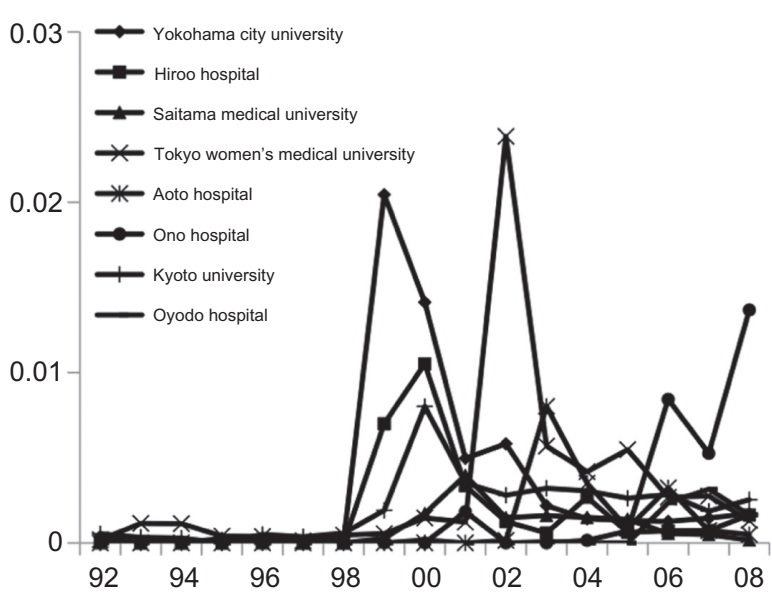

B

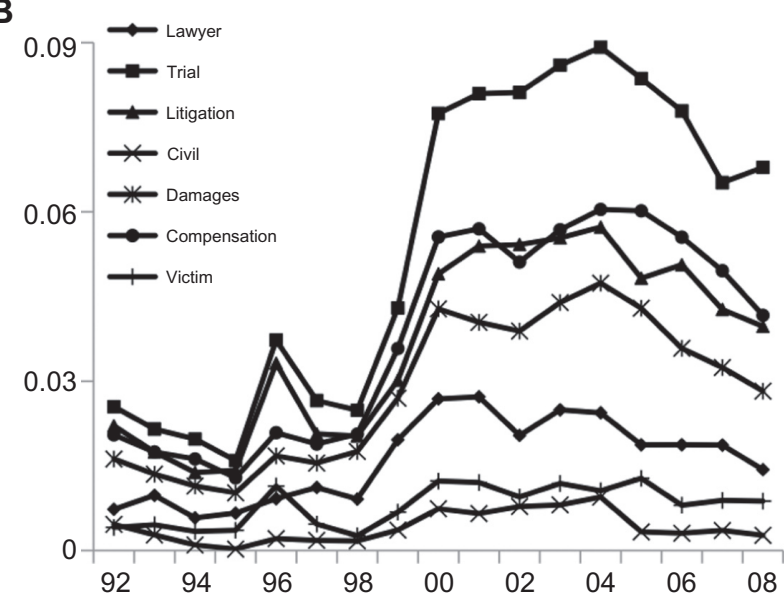

C

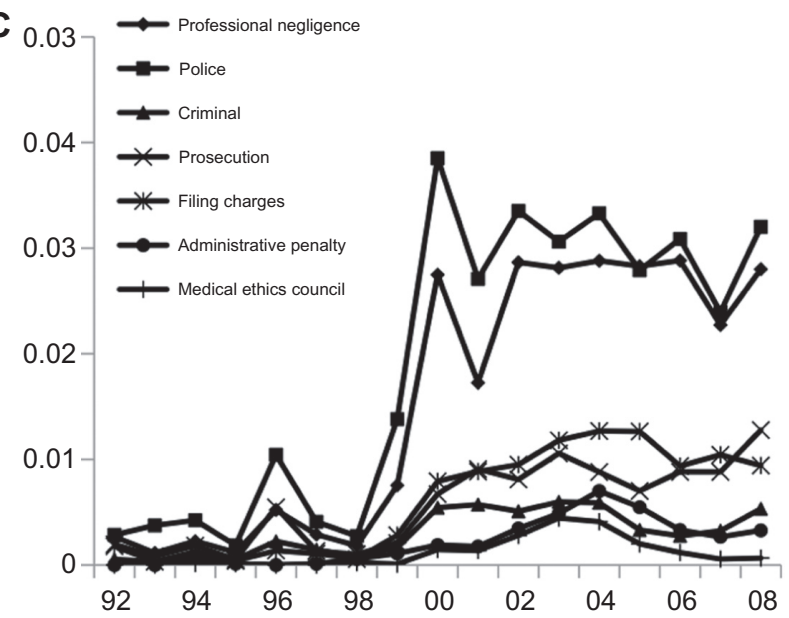

D

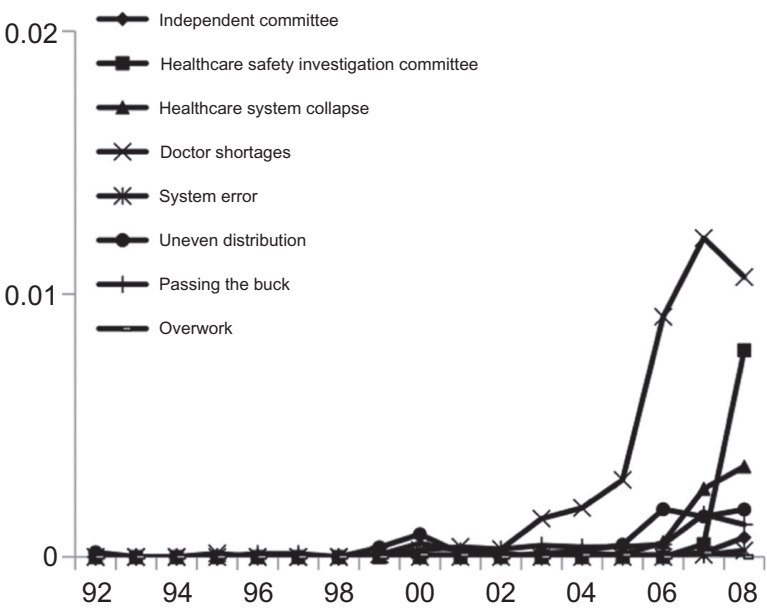

Figure 4 Annual trends in the usage frequency of each keyword. A) Hospital name, B) Litigation related, C) Punishment related, D) Healthcare system related.

In 2004 the media coverage of medical accidents in Japan began to change. Reports of major medically related occurrences $^{5-7}$ continued from 1999 to 2001 and served to make the public aware of the occurrence of these incidents. Also, until the Supreme Court ruling on the Tokyo Metropolitan Hiroo Hospital incident was made in $2004,{ }^{14}$ medically related occurrence reports focused on 'litigation' and 'punishment' (Figure $4 \mathrm{~B}$ and $\mathrm{C}$ ), while reports regarding 'system errors' and 'investigations into causes' were sporadic (Figure 4D). However, the number of reports relating to system errors and investigations into causes has been on the rise since this ruling, albeit gradually (Figure 4D). This situation resembles that in the United States, in which society's interest in medically related occurrence increased as a result of sensationalist media coverage and attention was initially paid to the punishment of doctors, but a consensus was eventually reached that it is important to consider the underlying system errors in order to decrease the number of medically related occurrence. ${ }^{16}$ If society is to form a consensus regarding medically related occurrences, it is necessary to have both incidents that act as triggers for long-term discussions.
The state of medical reporting in Japan underwent a major change in 2006 with the arrest of an obstetrician employed at the Fukushima Prefectural Ono Hospital. ${ }^{11}$ In this incident, images of the obstetrician arrested for professional negligence and involuntary manslaughter were broadcast nationwide; invoking a backlash from the healthcare community and the wider public, and heightening the discussion regarding medical accidents. In reality, the use of the word 'iryokago (medical professional negligence or error) in newspapers decreased from 2006 and started to be replaced by the word 'iryojiko' (medically related occurrence, event, or incident) (Figure 3). Additionally, the legal trial surrounding this case in 2007-2008 saw sharp increases in the frequency of the words 'system error' and 'investigation' as well as words relating to the background of medical accidents such as 'doctor shortages' and 'healthcare system collapse'. After years of discussions, such changes have led to a deeper public understanding of medically related occurrences and it could be considered that the Fukushima Prefectural Ono Hospital incident acted as the trigger for the forming of a consensus. 
Differences were found in how newspapers reported medical accidents. There were no differences in the frequency of the use of the word 'iryokago' (medical professional negligence or error), and all newspapers investigated showed sharp decreases in usage frequency. On the other hand, there were twice as many reports containing the expression 'iryojiko' (medically related occurrence, event, or incident) in the Yomiuri Shimbun than in any of the other four newspapers. This implies that, although there are differences between newspapers with regard to the emphasis of their medical malpractice coverage, all newspapers are restricting their use of the expression 'iryokago' (medical professional negligence or error) and are attempting to conduct composed, balanced analyses.

Medically related occurrences are closely related to medical litigation and have the potential to impact the healthcare system. Medically related occurrences and medical litigation could be seen as sources of friction between the healthcare community and the public, so it is therefore vital that trends in public opinion regarding these matters are accurately gauged. Although our study provides useful information, some limitations need to be discussed. While newspapers exert a major influence on public opinion, it is also important to assess how newspapers report medically related occurrences when it is considered that newspapers reflect public opinion. However, it would not have been possible to conduct such an investigation if a database of newspaper archives had not been created and made cheaply available. We were able to carry out this study due to the fact that a searchable database containing all newspaper articles published in Japan has been created and made available over the Internet. This resembles how information technology such as PubMed has changed the face of medical research. There have recently been a variety of studies conducted into the relationship between healthcare and the media ${ }^{4,17,18}$ but the creation and accessibility of databases is likely to accelerate the progress of such studies. Newspapers were the subject of this particular study but it is necessary to conduct similar investigations into other media such as television, magazines, and the Internet. However, databases have not yet been created for these alternative forms of media.

Risk Management and Healthcare Policy

\section{Publish your work in this journal}

Risk Management and Healthcare Policy is an international, peerreviewed, open access journal focusing on all aspects of public health, policy, and preventative measures to promote good health and improve morbidity and mortality in the population. The journal welcomes submitted papers covering original research, basic science, clinical \& epidemio-

\section{Acknowledgment}

The present research was funded by Health and Labour Sciences Research Grant by the Ministry of Health, Labour and Welfare, Japan.

\section{Disclosure}

The authors declare no conflicts of interest in this work.

\section{References}

1. Ricketts DW. Jury verdicts and the medical malpractice insurance crisis. Western J Med. 1976;124(2):169-171.

2. Roush W. Dana-Farber death sends a warning to research hospitals. Science. 1995;269(5222):295-296.

3. Havens DH, Boroughs L. "To err is human": a report from the Institute of Medicine. J Pediatr Health Care. 2000;14(2):77-80.

4. Stebbing C, Kaushal R, Bates DW. Pediatric medication safety and the media: what does the public see? Pediatrics. 2006;117(6):1907-1914.

5. Nakajima K, Keyes C, Kuroyanagi T, Tatara K. Medical malpractice and legal resolution systems in Japan. JAMA. 2001;285(12):1632-1640.

6. Furuse A. [What we must learn from recent medical accidents experiences at the investigation committee]. Gan To Kagaku Ryoho. 2001;28(3):310-316.

7. Yasunaga $\mathrm{H}$. Legal intervention against medical accidents in Japan. Risk Mgmt Health Care Pol. 2008;1:39-42.

8. Attal M, Harousseau JL, Stoppa AM, et al. A prospective, randomized trial of autologous bone marrow transplantation and chemotherapy in multiple myeloma.[ Intergroupe Francais du Myelome]. N Engl J Med. 1996;335(2):91-97.

9. Furukawa T, Kitajima M. [State of the art and problems in medical safety management]. Nippon Geka Gakkai Zasshi. 2002;103(3):309-313.

10. Kodama Y. [Institutional investigations on clinical adverse events]. Kyobu Geka. 2009;62(2):145-148.

11. Nagamatsu S, Kami M, Nakata Y. Healthcare safety committee in Japan: mandatory accountability reporting system and punishment. Curr Opinion Anaesthesiol. 2009;22(2):199-206.

12. Robbennolt JK, Studebaker CA. News media reporting on civil litigation and its influence on civil justice decision making. Law Human Behav. 2003;27(1):5-27.

13. Lupton D, McLean J. Representing doctors: discourses and images in the Australian press. Social Sci Med. 1998;46(8):947-958.

14. Idegawa M. Medical accidents reportage (in Japanese), Asahi Shimbun Publications Inc.: Tokyo, 2009.

15. Spritz N. Oversight of physicians' conduct by state licensing agencies. Lessons from New York's Libby Zion case. Ann Int Med. 1991;115(3):219-222.

16. Homsted L. Institute of Medicine report: to err is human: building a safer health care system. Fl Nurse. 2000;48(1):6.

17. Caspermeyer JJ, Sylvester EJ, Drazkowski JF, Watson GL, Sirven JI. Evaluation of stigmatizing language and medical errors in neurology coverage by US newspapers. Mayo Clinic Proc. 2006;81(3):300-306.

18. Kishi Y, Nagamatsu S, Takita M, et al. Trends in cancer coverage in Japanese newspapers. J Clin Oncol. 2008;26(36):6017-6020.

\footnotetext{
Submit your manuscript here: http://www.dovepress.com/risk-management-and-healthcare-policy-journal
}

logical studies, reviews and evaluations, guidelines, expert opinion and commentary, case reports and extended reports. The manuscript management system is completely online and includes a very quick and fair peerreview system, which is all easy to use. Visit http://www.dovepress.com/ testimonials.php to read real quotes from published authors. 